\title{
Preliminary Results of a Novel Designed 7.7 kJ Plasma Focus Device with Hemisphere Electrodes
}

\author{
M. E. Abdel-kader ${ }^{\mathrm{a}, ~}{ }^{*}$ and M. A. Abd Al-Halim ${ }^{\mathrm{b}}$ \\ (a) Plasma and Nuclear Fusion Department,, Nuclear Research Center (N.R.C.), Egyptian Atomic Energy Authority, Egypt \\ ${ }^{(b)}$ Physics Department, Faculty of Science, Benha University, Benha, Egypt
}

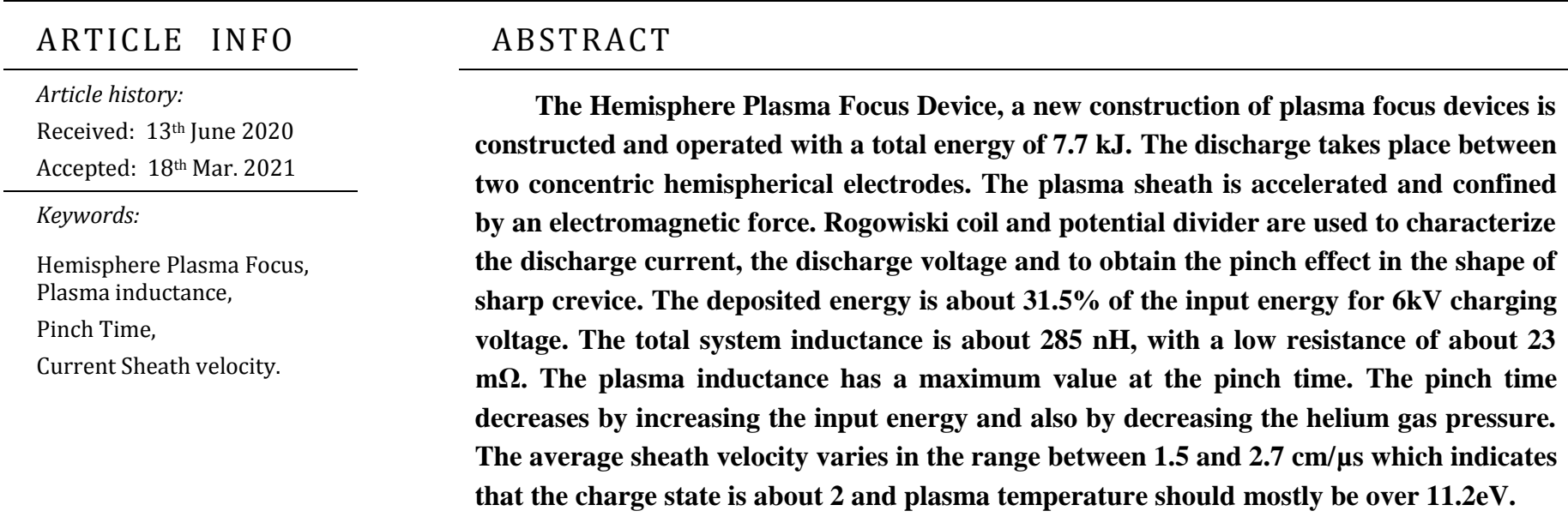

\section{INTRODUCTION}

The plasma focus experiments have been used to generate, accelerate and confine the plasma by electromagnetic forces. These experiments have been developed in two configurations by Mather $[1,2]$ and by Filippov [3] which differ mainly in their aspect ratios of the inner electrode (length/diameter), so they directly affect the motion of plasma sheath in the axial and the radial phases experimentally and also in the different models which were developed $[4,5]$. The current sheath motion [4] and the lifetime of the pinch [6] in the cylindrical devices were simulated using both the snowplow and slug models. The mass and current factors [7] were also added to the model to represent the shedding effects.

The spherical plasma focus (SPF) machine is considered as a case combining both Mather and Filippov configurations. The SPF devices were suggested early by Makeev in 1996 [8]. The mixture of deuterium-tritium gas is used in the SPF experiment to create a high neutron yield of about $10^{13}$ [9] and the snowplow model is used to simulate the sheath motion in spherical and hemispherical devices [10, 11]. The profile and dynamics of the current sheath were investigated by measuring the velocity and distribution of current sheath via the magnetic probe [12] as a Filippov type plasma focus device [13].

The present work aims to investigate the new configuration of Hemisphere Plasma Focus device. The plasma discharge and the plasma dynamics are described inside the discharge chamber of HSPF. The experimental results include the discharge current, the discharge voltage behavior, inductance and resistance of the system, plasma inductance, pinch time and estimation of the sheath velocity.

\section{Experimental Setup and Sheath Dynamics}

The Hemisphere Plasma Focus device (HSPF) is constructed as shown in Figure (1). The electric circuit includes the power supply of $12 \mathrm{kV}$ maximum charging voltage, an ignitron. The main condenser bank consists of six capacitors, each of $18 \mu \mathrm{F}$, so that the total capacitance is about $108 \mu \mathrm{F}$ and the maximum input energy is about $7.7 \mathrm{~kJ}$. 




a)

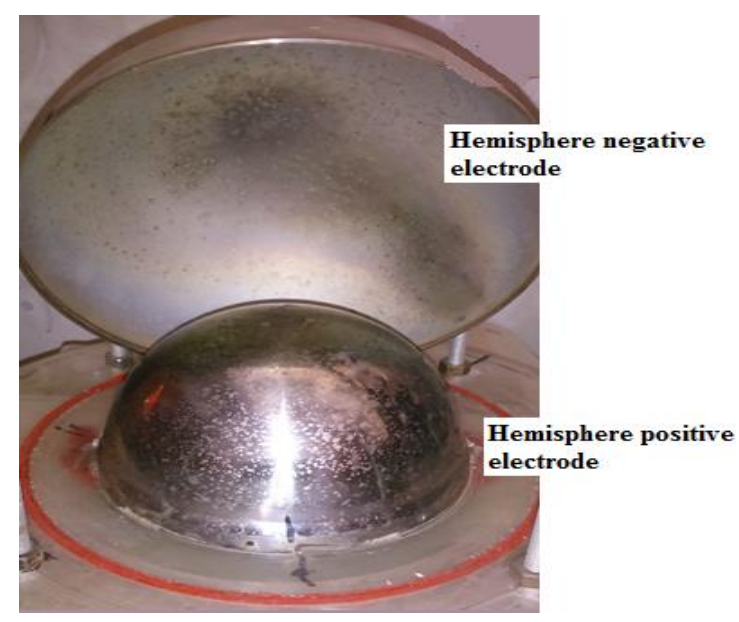

b)

Fig. (1. a): The electric circuit and b) A photograph of HSPF device
The discharge chamber consists of two concentric hemispherical electrodes made from stainless steel. The outer electrode is considered the cathode of $10 \mathrm{~cm}$ radius while the inner electrode is the anode of $7.5 \mathrm{~cm}$ radius, so the gap distance which separates the two electrodes is about at $2.5 \mathrm{~cm}$. An insulator disc made of Perspex is placed at the gap between the two electrodes to prevent any spark that may occur. The main specifications of the experiment are given in Table (1).

Table (1): General Specifications of HSPF Device

\begin{tabular}{l|l}
\hline \multicolumn{1}{c|}{ Element } & \multicolumn{1}{c}{ Value } \\
\hline $\mathrm{E}_{\max }$ & $7.7 \mathrm{~kJ}$ \\
$\mathrm{~V}_{0}$ & 2 to $12 \mathrm{kV}$ \\
$\mathrm{C}_{0}$ & $108 \mu \mathrm{F}$ \\
$\mathrm{P}_{0}$ & 0.6 to $1.2 \mathrm{Torr}$ \\
Gas type & Helium \\
Anode radius & $7.5 \mathrm{~cm}$ \\
Cathode radius & $10 \mathrm{~cm}$ \\
Electrode material & Stainless steel \\
\hline
\end{tabular}

Figure (2) shows the ignitron circuit which is used to discharge the condenser bank into the HSPF electrodes. Chopper circuit is used to convert the input of 12VDC to the $12 \mathrm{VAC}$, then it is converted to $700 \mathrm{VAC}$ using ferrite core transformer, and finally it is converted to the 700 VDC by rectifier circuit to charge the trigger capacitor.

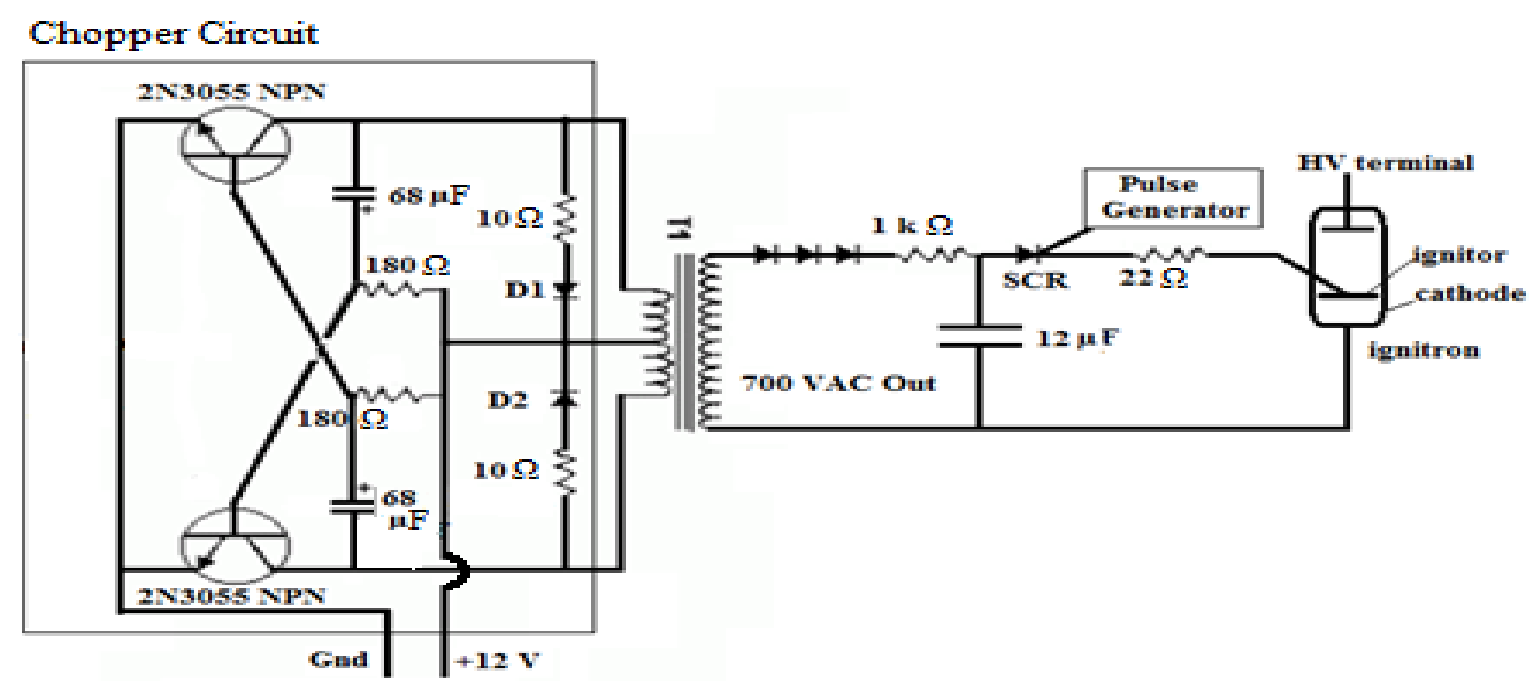

Fig. (2): Schematic diagram of electric circuit of ignitron 
The trigger capacitor $(12 \mu \mathrm{F}, 800 \mathrm{~V})$ discharges between the two electrodes of ignitron in order to vaporize the mercury as shown in Figure (2). The HV power supply charges the main condenser bank, which is discharged into the two hemispherical electrodes via trigger circuit, forming the plasma sheath at the insulator between the two electrodes[14].

The helium gas between the hemispherical electrodes is ionized by discharging of the high voltage and forming a plasma current sheath (CS) as shown in Figure (3). After breakdown of the helium gas, the CS moves from the equator to the antipodal by Lorentz force. A high discharge current, $\mathrm{I}_{\mathrm{r}}$ flows in the radial direction between the two hemispherical electrodes, and an induced magnetic field $\mathrm{B}_{\varphi}$ will be in azimuthal direction. Therefore, Lorentz force $F_{\theta}$ is generated and deflects the CS with in the direction of angle $\theta$. The plasma CS will be confined and the pinch is formed at the antipodal point $[11,15]$.

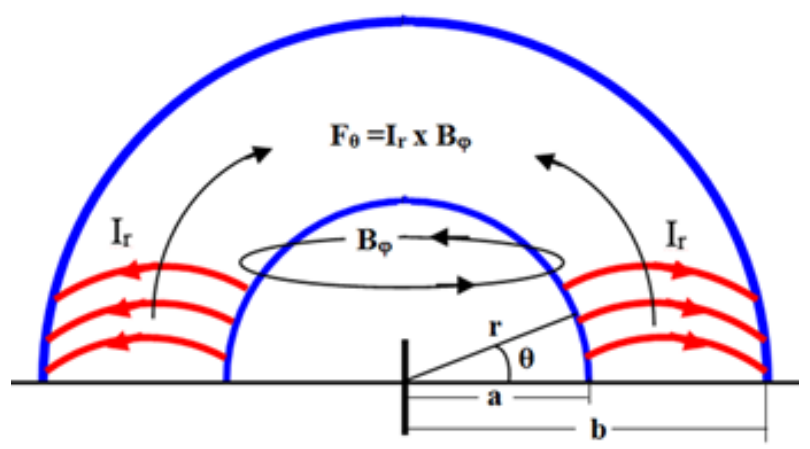

Fig. (3): Schematic diagram of the forces direction in HSPF

\section{EXPERIMENTAL RESULTS}

\section{Electrical characteristics}

The electric circuit of the HSPF device is shown in Figure (1). When the condenser bank is discharged between the two hemispherical electrodes, the helium gas is ionized and breakdown occurred, forming a symmetric CS. A Few microseconds later, the current increases, and the sheath moves in the $\theta$-direction under Lorentz force then, it forms the pinch column[15].

The total discharge current and discharge voltage are measured using Rogowiski coil and potential divider respectively. The I-V waveform is shown in Figure (4) for $\mathrm{P}_{0}=0.6$ Torr and $\mathrm{V}_{0}=6 \mathrm{kV}$. The Figure shows that the pinch occurs at time of about $5.6 \mu \mathrm{s}$ in which a clear crevice shape appears in the discharge current signal $[10,16]$. Rogowiski coil is calibrated, so that the discharge current I is related to the output voltage on oscilloscope $\mathrm{V}_{\text {out }}$ as follows:

$\mathrm{I}(\mathrm{kA})=$ Const. $\times \mathrm{V}_{\text {out }}(\mathrm{V})$ and Const. $=70.4 \Omega^{-1}$

The potential divider is also calibrated to measure the discharge voltage $\mathrm{V}$ as a function of the output voltage on the oscilloscope $\mathrm{V}_{\text {osc }}$ and it was found that $\mathrm{V}=250 \mathrm{~V}_{\text {osc }}$.

The present experiment was repeated several times (may be 5 times at least) for each input discharge conditions $\left(\mathrm{V}_{0}\right.$ and $\left.\mathrm{P}_{0}\right)$ to verify the accuracy. For example, the change of the discharge current is about $\pm 2 \mathrm{kA}$ ( $\mathrm{I} \approx 112 \mathrm{kA}$ ) for $\mathrm{V}_{0}=8 \mathrm{kV}$, while the pinch time is almost the same, which represents a good accuracy.

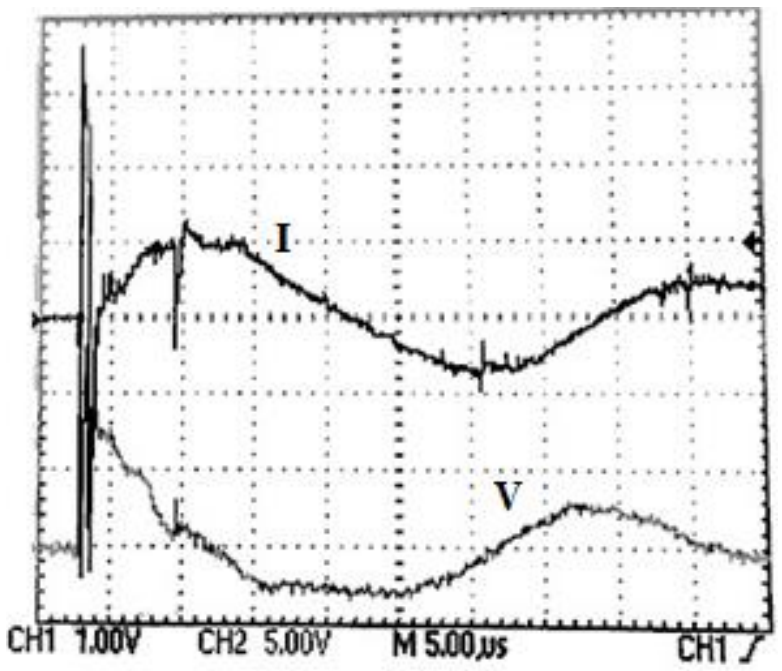

Fig. (4): Trace signal of the discharge current (upper signal) and voltage (lower signal) for $6 \mathrm{kV}$ charging voltage and 0.6Torr of helium gas pressure

The peak of the discharge current is calculated theoretically from the relation:

$$
I_{\text {Theoretical }}=\frac{\pi C_{0} V_{0}\left(1+f_{r}\right)}{\tau}
$$

Where $\mathrm{f}_{\mathrm{r}}$ is the reversal ratio which is given by:

$$
f_{r}=\frac{1}{4}\left(\frac{V_{5}}{V_{4}}+\frac{V_{4}}{V_{3}}+\frac{V_{3}}{V_{2}}+\frac{V_{2}}{V_{1}}\right)
$$

The potentials $\mathrm{V}_{1}, \mathrm{~V}_{2}, \mathrm{~V}_{3}, \mathrm{~V}_{4}$, and $\mathrm{V}_{5}$ are the output peaks of the discharge current signal, $\mathrm{V}_{0}$ is charging voltage, $\mathrm{C}_{0}$ is the capacitance of condenser bank, and $\tau$ is the time period of the signal. Figure (5) shows the variation of the experimental and theoretically calculated values of the peak discharge 
currents, $\mathrm{I}_{\text {(Experimental) }}$ and $\mathrm{I}_{\text {(Theoretical) }}$ respectively, as a function of the input energy $\left(E_{0}=\frac{1}{2} C_{0} V_{0}^{2}\right)$.

The HSPF device has a constant circuit inductance $\mathrm{L}_{0}$ which is calculated by considering the resonance circuit equation [17]:

$$
\omega=\sqrt{\frac{1}{\mathrm{~L}_{0} \mathrm{C}_{0}}}
$$

where $\omega$ is the angular frequency of the discharge circuit. The calculated total circuit inductance of HSPF device is $285 \mathrm{nH}$. The total circuit resistance $R_{0}$ of HSPF is calculated by the relation $[14,16]$ :

$$
\mathbf{I}=\mathbf{I}_{0} \sin (\omega \mathrm{t}) \exp \left(-\mathbf{R}_{0} \mathrm{t} / 2 \mathbf{L}_{0}\right)
$$

For the peak current, i.e. $\sin (\omega t)=1$, the total circuit resistance is calculated from the relation between $\ln \left(\mathrm{I} / \mathrm{I}_{0}\right)$ and the discharge time. The calculated value of $R_{0}$ in the HSPF device is $23 \mathrm{~m} \Omega$ which indicates that the total resistance of the circuit is small as compared to the circuit impedance.

The deposited energy, $\mathrm{E}_{\mathrm{d}}$, is obtained by integrating the power $\mathrm{P}_{\mathrm{w}}$ using the discharge current and the discharge voltage across the chamber itself as [18, 19]:

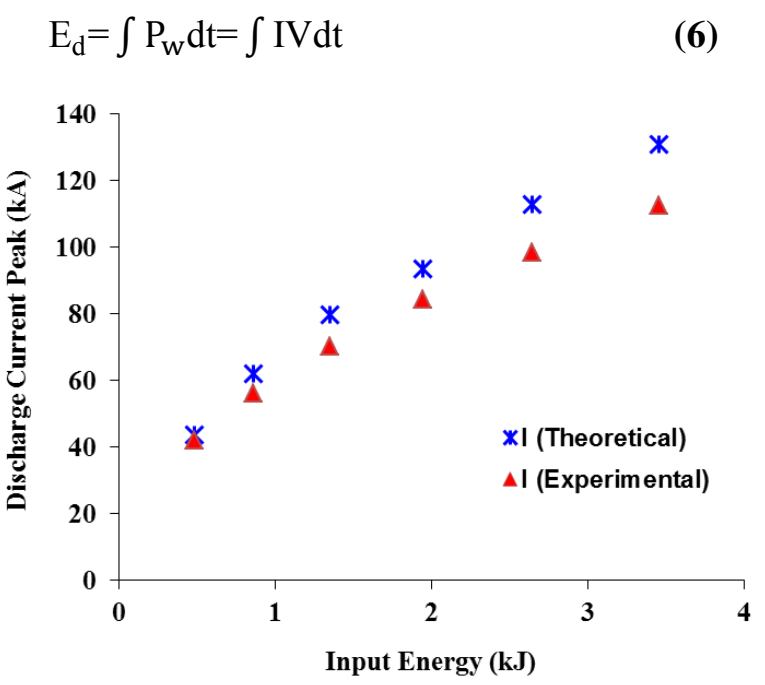

Fig. (5): The experimental and theoretical discharge current peaks in the HSPF as a function of the input energy.

The deposited energy is about $0.61 \mathrm{~kJ}$ for a $6 \mathrm{kV}$ charging voltage, which is corresponding to a peak power of about 94 MW. Figure (6) shows the variation of both the deposited energy $E_{d}$ and the input energy $\mathrm{E}_{0}$. The ratio $\mathrm{E}_{\mathrm{d}} / \mathrm{E}_{0}$ is about $31.5 \%$. The difference between the energies can be attributed to the energy losses by the circuit resistance, inductance and ionization of the neutral gas.

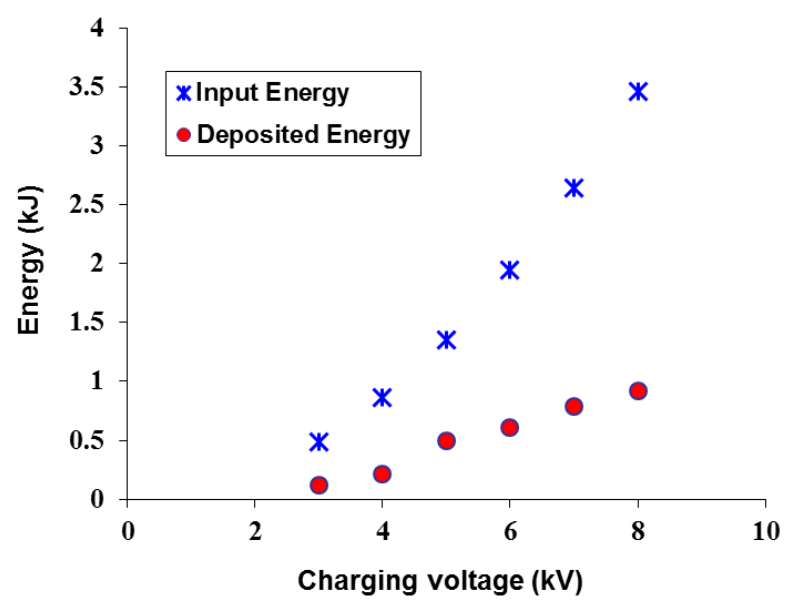

Fig. (6): The input and deposited energies in the HSPF system for helium gas pressure of 0.6 Torr

\section{Pinch time}

The pinch time, $t_{p}$, could be defined as the time needed to form the pinch after the gas breakdown [20]. It could be detected as the minimum value of the discharge current derivative $[14,21]$ and it is also considered as the time at which the dip/crevice appears in the discharge current trace [16].

After the gas breakdown, the CS is formed at the insulator in the region between the two hemispherical electrodes. The discharge current flows in the radial direction and the induced magnetic field will be generated in the $\varphi$-direction, hence the generated Lorentz force will derives the CS in $\theta$-direction which finally creates the pinch. The pinch evidence is detected in the discharge current signal as a sharp crevice (a sudden decrease followed by current raise in a very short time). This occurs when the plasma CS is compressed, where the magnetic pressure $\mathrm{P}_{\mathrm{m}}=\mathrm{B}_{\varphi}{ }^{2} / 2 \mu_{\mathrm{o}}$ exceeds the kinetic pressure $P_{k}=$ NKT that leads finally to the compression process which increases the plasma inductance and reduces the discharge current [16], then the CS is expanded giving rise and increase of the discharge current [22,23].

The pinch time of the crevice is inversely proportional to the input energy as shown in 
figure 7 [22, 23], due to increasing of Lorentz force which tends to compress the sheath faster, so the pinch time decreases. Also, the pinch time for the higher gas pressure (1.2 Torr) is higher than that of low pressure. This is because of the heavier mass that needs more energy to be compressed and also due to the higher kinetic pressure that resists the compression.

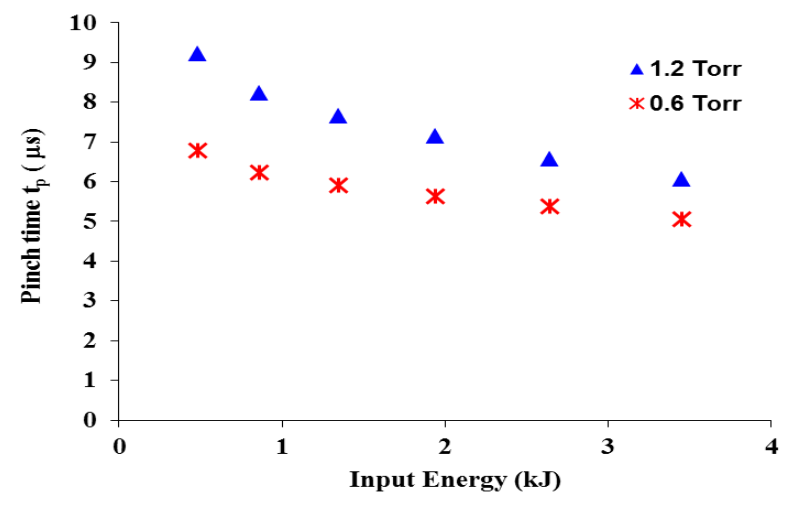

Fig. (7): The pinch time as a function of the input energy

\section{Plasma inductance}

The plasma inductance is inversely proportional to the pinch radius. Therefore, the minimum pinch radius, which is associated with a rapid rise of the magnetic flux $\Phi$, leads to a minimum value of the discharge current derivative and a higher value of the plasma inductance [14]. The voltage drop across the plasma $\mathrm{V}(\mathrm{t})$ is mainly due to the plasma inductance $L_{p}$ which is varying with time. Therefore, the plasma inductance could be calculated by integrating the discharge voltage numerically and dividing by the current $[14,16]$ according to the relation:

$$
L_{p}(t)=\frac{\int_{0}^{t} V(t) d t}{I(t)}
$$

Figure (8) illustrates the variation of both the current derivative $\mathrm{d} / / \mathrm{dt}$ and the plasma inductance $\mathrm{L}_{\mathrm{p}}$ as a function of the discharge time. It shows that the pinch occurs at discharge time of about $5.6 \mu \mathrm{s}$ which is corresponding to the maximum increase of the plasma resistance associated with the minimum value of $\mathrm{d} / \mathrm{dt}$.

Using Ampere's law, the magnetic field can be written as $[10,11]$ :

$$
\mathrm{B}=\frac{\mu_{0} \mathrm{If}_{\mathrm{c}}}{2 \pi \mathrm{r} \cos \theta}
$$

Where $\mu_{\mathrm{o}}$ is the permeability of free space, $f_{c}$ is the current factor due to current shedding [4], and $\mathrm{r}$ is the radius at which the magnetic field is calculated. According to the magnetic flux relation; $\Phi=\int \mathrm{B} d \mathrm{~S}$, then one can get $\Phi$ by integration over the area $\mathrm{dS}=\mathrm{rd} \theta \mathrm{dr}$ so that [24];

$$
\Phi=\frac{\mu_{0} \text { If }_{c}}{2 \pi} \int_{0}^{\theta} \int_{a}^{b} \frac{\mathrm{drd} \theta}{\cos \theta}
$$

Therefore, the plasma inductance could be given as[24]:

$$
\mathrm{L}_{\mathrm{p}}=\frac{\Phi}{\text { If }_{\mathrm{c}}}=\frac{\mu_{0}(\mathrm{~b}-\mathrm{a})}{2 \pi} \ln (\sec \theta+\tan \theta)_{0}^{\theta}
$$

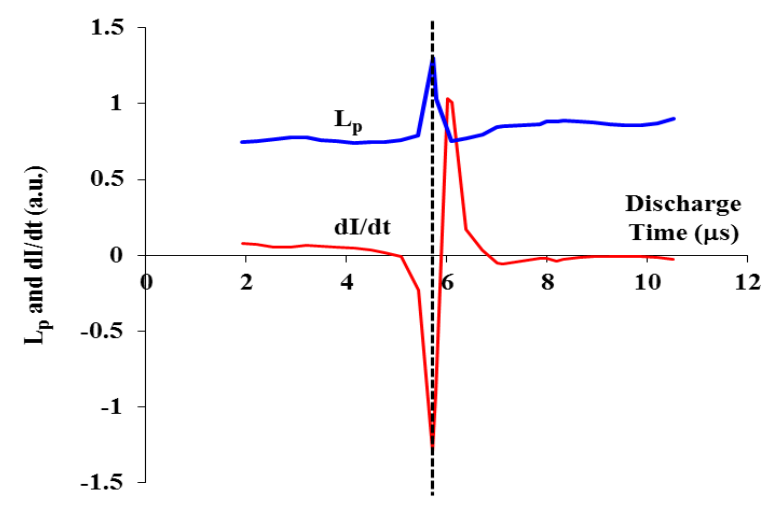

Fig. (8): Variation of the current derivative and the plasma inductance as a function of the discharge time, for $6 \mathrm{kV}$ charging voltage and pressure of $0.6 \mathrm{Torr}$

Figure (9) illustrates the variation of the plasma inductance as a function of the angle of motion according to the equation 10 [25]. The Figure shows that the $\mathrm{L}_{\mathrm{p}}$ is increased as the plasma moves from the equator $\left(\theta=0^{\circ}\right)$ to the antipodal $\left(\theta=90^{\circ}\right)$ according to equation (10). The Figure shows also that $\mathrm{L}_{\mathrm{p}}$ reaches a maximum of about $23 \mathrm{nH}$ for angle nears $89^{\circ}$, corresponding to the maximum confinement conditions in the present experiment (highest charging voltage of $8 \mathrm{kV}$ and low gas pressure of 0.6 Torr). Therefore, the CS is experiencing a maximum confinement and hence a highest inductance. On the other hand, when the input conditions charging voltage is only $3 \mathrm{kV}$ and the gas pressure is 1.2 Torr, the confinement is 
weaker. Hence, the CS can only reach an angle of about $86^{\circ}$ with a lower value for $\mathrm{L}_{\mathrm{p}}$ of about $17 \mathrm{nH}$.

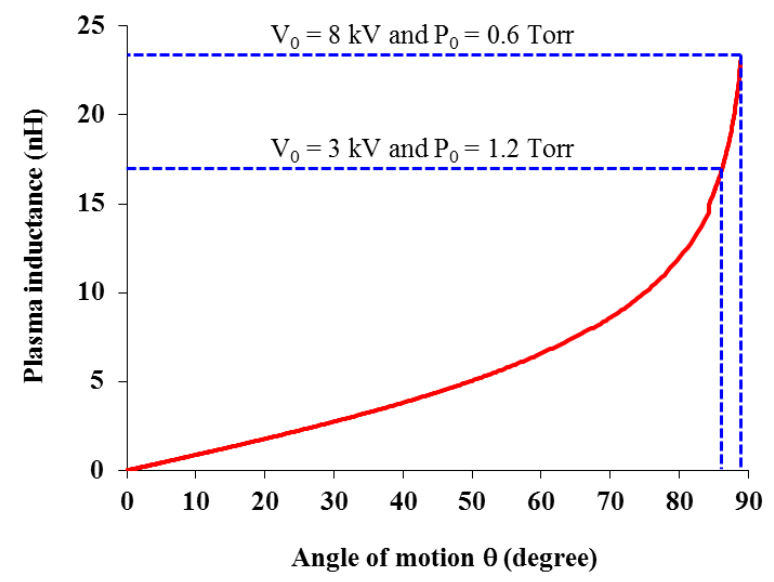

Fig. (9): Variation of the plasma inductance as a function of the angle of motion

\section{Velocity and temperature}

The average plasma sheath velocity is calculated by dividing the arc length by the pinch time $t_{p}$. Figure (10) shows that the sheath velocities are in the range between 1.5 and $2.7 \mathrm{~cm} / \mu \mathrm{s}$. The velocity increases with increasing of the deposited energy to the pinch time $\mathrm{E}_{\mathrm{dp}}$. Also, the velocity is higher for the low gas pressure due its light mass. The total mass, which is swept by the plasma sheath, is calculated depending on the snow plow model by means of the volume $\mathrm{V}$ between the two hemispherical electrodes which contains the ionized gas. This volume is expressed as:

$$
\mathrm{V}=\frac{2}{3} \pi\left(\mathrm{b}^{3}-\mathrm{a}^{3}\right)
$$

The deposited energy to the pinch time $\mathrm{E}_{\mathrm{dp}}$, can be expressed as:

$$
\mathrm{E}_{\mathrm{dp}}=\mathrm{E}_{\mathrm{m}}+\mathrm{E}_{\mathrm{k}}+\mathrm{E}_{\mathrm{t}}+\mathrm{E}_{\mathrm{i}}
$$

Where $E_{m}$ is the magnetic induction stored energy, $E_{k}$ is the kinetic energy, $E_{t}$ is the internal energy due to thermal motion, and $\mathrm{E}_{\mathrm{i}}$ is the total ionization energy [18]. The quantities in the last equation are given by:

$$
\begin{aligned}
& E_{d p}=\int_{0}^{t_{p}} I_{c} V \\
& E_{k}=1 / 2 N m_{i} v^{2} \\
& E_{t}=1.5 N \mathrm{NkT}(Z+1) \\
& E_{m}=0.5 L_{p} I^{2} \\
& E_{i}=N Z \sum I_{i}
\end{aligned}
$$

Where $\mathrm{m}_{\mathrm{i}}$ is the helium ion mass, $\mathrm{N}$ is number of helium ions ionized and swept, $\mathrm{V}$ is the average sheath velocity, $\mathrm{k}$ is Boltzmann's constant, $\mathrm{T}$ is the plasma temperature, $\mathrm{Z}$ is the charge state, and $\mathrm{I}_{\mathrm{i}}$ represents the ionization potential of helium gas $\left(\mathrm{I}_{1}=24.6 \mathrm{eV}\right.$ and $\left.\mathrm{I}_{2}=54.4 \mathrm{eV}\right)$.

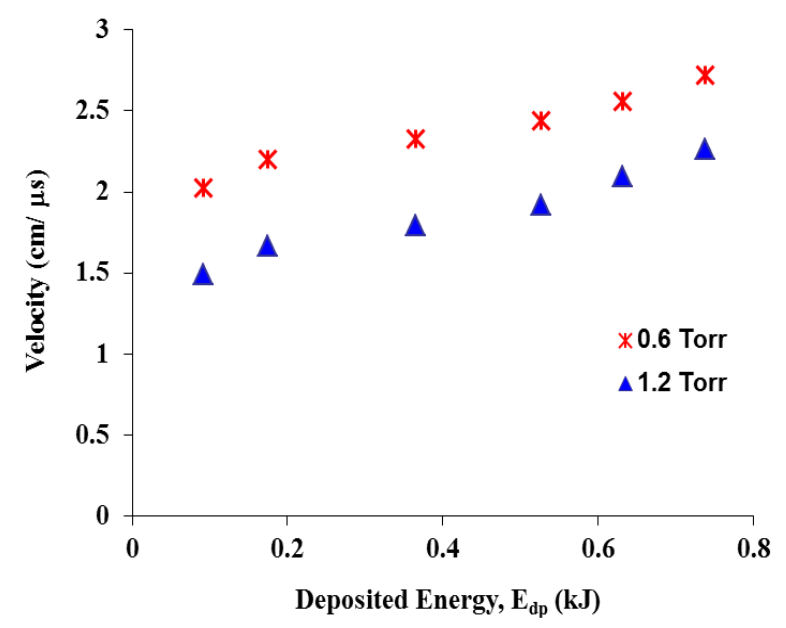

Fig. (10): The relation between the plasma sheath velocity and charging voltage to the pinch $E_{d p}$.

The corona model is used to calculate the plasma temperature depending on the charge state, so it is possible that $\mathrm{T}=2.3 \mathrm{eV}$ for $\mathrm{Z}=0.5, \mathrm{~T}=$ $4 \mathrm{eV}$ for $\mathrm{Z}=1, \mathrm{~T}=6 \mathrm{eV}$ for $\mathrm{Z}=1.5$, and $\mathrm{T}=12 \mathrm{eV}$ for $Z=2$ [26-28]. These values of the charge state inform about the possibility of different temperatures to take place.

The total initial mass of helium gas between the two hemispherical electrodes is about $\mathrm{m}_{0}=$ $0.16 \mathrm{mg}$. Figure 11 shows the possible cases of different maximum swept masses as a function of the deposited energy to the pinch time $E_{d p}$, for charge states of $\mathrm{Z}=0.5,1,1.5$, and 2 . These cases differ in temperature and charge state, so the maximum swept mass is affected according to equations 13 to 17 . The most probable value of the charge state is in the range between 1.5 and 2 and is almost likely to be closer to $\mathrm{Z}=2$. For example, in case of $6 \mathrm{kV}$ charging voltage $\left(\mathrm{E}_{\mathrm{dp}}=0.4 \mathrm{~kJ}\right)$ and the charge state of $\mathrm{Z}=1.5$ (plasma temperature of $6 \mathrm{eV}$ ), the calculated maximum swept mass $\mathrm{m}_{\mathrm{s}}$ is about $0.17 \mathrm{mg}$ which is slightly higher than that of the initial helium gas mass $\left(\mathrm{m}_{0}=0.16 \mathrm{mg}\right)$.

For a higher charging voltage, the calculated maximum swept mass may exceed $0.2 \mathrm{mg}$ which is higher than the allowed gas mass. On the other hand, for a higher charging voltage of $8 \mathrm{kV}\left(\mathrm{E}_{\mathrm{dp}}=\right.$ 
$0.55 \mathrm{~kJ})$, for a higher charge state $(\mathrm{Z}=2$ and plasma temperature $\geq 11.2 \mathrm{eV}$ ) which is the typical value of $\mathrm{m}_{\mathrm{s}}=0.13 \mathrm{mg}$ which is acceptable since it is lower than $\mathrm{m}_{0}$. Also, for a $3 \mathrm{kV}$ charging voltage $\left(\mathrm{E}_{\mathrm{dp}}=\right.$ $0.075 \mathrm{~kJ}), \mathrm{m}_{\mathrm{s}}$ is about $0.019 \mathrm{mg}$ which is about $12 \%$ of the initial mass $m_{0}$. This ratio is close to that which was used in Lee model, and in order to get more accurate value, some other terms could be added to equation 12. Adding some other terms like the radiation energy and the ablation energy will reduce the energy gained by the gas ions for motion, and therefore can help to get more accurate values of $m_{s}$. In the present study, It could be concluded that the charge state is almost $\mathrm{Z}=2$, and the plasma temperature is mostly over $11.2 \mathrm{eV}$.

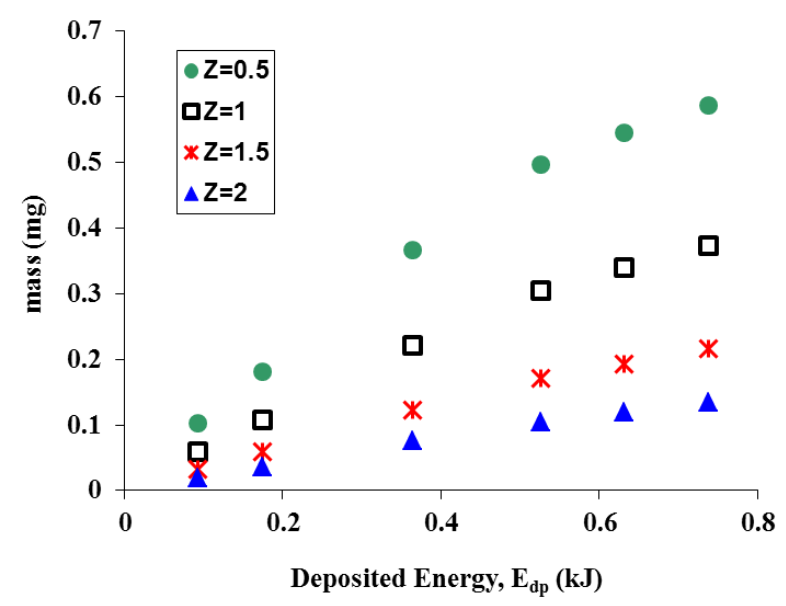

Fig. (11): The relation between the swept mass and the deposited energy to the pinch $E_{d p}$

\section{CONCLUSION}

The Hemisphere Plasma Focus (HSPF) device is a new promising structure of plasma focus devices. The discharge occurs between two concentric hemisphere electrodes. The plasma sheath was accelerated and confined by an electromagnetic force due to the magnetic pressure which is higher than the kinetic pressure.

The total system inductance was about $285 \mathrm{nH}$ while the total system resistance was $23 \mathrm{~m} \Omega$ with a deposited energy of about $31.5 \%$ for $6 \mathrm{kV}$ charging voltage. The preliminary results, using the helium gas, showed a sharp crevice that appeared in the discharge current signals which is considered an evidence of pinch creation. The derivative of the discharge current signals indicates that the plasma inductance has a higher value due to the higher magnetic flux at the pinch time. The analysis showed that the time of pinch decreased by increasing the input energy or by reducing the helium gas pressure.

The calculated average CS velocity varies between 1.5 and $2.7 \mathrm{~cm} / \mu \mathrm{s}$. The calculations showed that for swept mass is in the range between 0.019 and $0.13 \mathrm{mg}$, with plasma temperature of about $11.2 \mathrm{eV}$ and charge state of $\mathrm{Z}=2$.

\section{REFERENCES}

[1] J. W. Mather, Plasma Physics, Methods of Experimental Physics, 9B, 187, (Academic Press, New York, 1971).

[2] J.W. Mather, Phys. Fluids 7, S28 (1964).

[3] N.V. Filippov, T.I. Filippova, V.P. Vinogradov, Nucl. Fusion Suppl. 2, 577 (1962).

[4] S. LEE, J. Fus. Energ.. 33, 319 (2014).

[5] Siahpoush, V., M. A. Tafreshi, S. Sobhanian, and S. Khorram. "Adaptation of Sing Lee's model to the Filippov type plasma focus geometry." Plasma physics and controlled fusion 47, 7, 1065 (2005).

[6] S. Lee, J. Appl. Phys. 54, 3603, (1983).

[7] B. Shan, P. Lee, and S. Lee, Sing. J. Phys., 16, 25, (2000).

[8] N.G. Makeev, V.G. Rumyantsev, G.N. Cheremukhin, Physics and Engineering of Pulse Sources of Ionizing Radiations for Investigation of Fast Processes, Sarov, 281 (1996).

[9] N. V. Zavyalov, V. V. Maslov, V. G. Rumyantsev, I. Yu. Drozdov, D. A. Ershov, D. S. Korkin, D. A. Molodtsev, V. I. Smerdov, A. P. Falin, and A. A. Yukhimchuk; Plasma Physics Reports, 39, 3, 243-247 (2013).

[10] M. A. Abd Al-Halim; J. Fus. Energ, 29, 134140 (2010).

[11] Y. Ay, M. A. Abd Al-Halim, and M. A. Bourham, Eur. Phys. J. D, 69, 205, (2015).

[12] S. H. Saw, M. Akel, P. C. K. Lee, S. T. Ong, S. N. Mohamad, F. D. Ismail, N. D. Nawi, K. Devi, R. M. Sabri, A. H. Baijan, J. Ali, S. 
Lee; J Fusion Energ, 31, 411-417 (2012).

[13] M. A. Mohammadi, S. Sobhanian, M. Ghomeishi, E. Ghareshabani, M. Moslehifard, S. Lee, R. S. Rawat; J Fusion Energ, 28, 371-376 (2009).

[14] M. E. Abdel-kader, M. A. Abd Al-Halim, A. M. Shagar, H. A. Eltayeb, H. A. Algamal, and A. H. Saudy, J. Fus. Energ, 33, 53-59 (2014).

[15] T.E. Markusi, K.A. Polziny, J.Z. Levinez, C.A. McLeaveyx, and E.Y. Choueiri, AIAA, 17, 3257 (2000).

[16] M. E. Abdel-kader, M. A. Abd Al-Halim, A. M. Shagar and A. H. Saudy; Eur. Phys. J. D, 68: 160 (2014).

[17] R.A. Serway, J.W. Jewett, Physics for Scientists and Engineers with Modern Physics, 8th edn. (Brooks/Cole, Belmont, CA, 2010).

[18] H. A. El-Gamal, H. A. El-Tayeb, M. A. Hassouba, and M. Abdul-Moname, Plasma Devices and Operations, 14, 91, (2006).

[19] H. A. El-Gamal, M. A. Hassouba, H. A. ElTayeb, and M .Abdul-Moname, Fizika A, 13, 23, (2004).

[20] R. Verma, R. S. Rawat, P. Lee, A. T. L. Tan, H. Shariff, G. J. Ying, S. V. Springham, A. Talebitaher, U. Ilyas, and A. Shyam, IEEE Trans. Plasma Sci., 40, 12, 3280, (2012).
[21] F. Veloso, C. Pavez, J. Moreno, V. Galaz, M. Zambra, and L. Soto, J. Fus. Energ., 31, 30, (2012).

[22] M. Emami, Laser Phys. 17, 18 (2007).

[23] H. Ghomi, Sh. Rostami, H. Latifi, in 28th ICPIG, Prague, July 15-20 (2007)

[24] M. E. Abdel-Kader, M. A. Abd Al-Halim, A. M. Shagar and A. H. Saudy, "Investigation of a $5 \mathrm{~kJ}$ conical Z-pinch discharge," Eur. Phys. J. D, 68,160 (2014).

[25] M. E. Abdel-kader, M. A. Abd Al-Halim, "MHD Simulation of Hemispherical Plasma Focus Using Snowplow Model", Accepted for publication in Fusion Science and Technology (2020). DOI:10.1080/15361055.2020.1777675

[26] R. P. McWhirter in "Plasma Diagnostics Techniques", (Eds. R.H. Huddlestone and S.L. Leonard), Academic Press, New York, (1965).

[27] M. Akel, Sh. Al-Hawat, S. H. Saw, and S. Lee, J Fus. Energ, 29, 223, (2010).

[28] S. LEE, Radiative Dense Plasma Focus Computation Package: RADPF, 15 July 2011.

http://www.intimal.edu.my/school/fas/UFLF/F ile1RADPF.htm.

http//:www.plasmafocus.net/IPFS/modelpacka ge/File1RADPF.htm 